\title{
Determination of dissolved methane in natural waters using headspace analysis with cavity ring-down spectroscopy
}

\author{
Hannah M. Roberts, Alan M. Shiller* \\ Department of Marine Science, University of Southern Mississippi, 1020 Balch Blvd, Stennis Space Center, MS 39529, USA
}

\section{H I G H L I G H T S}

- A method for determining low nanomolar dissolved $\mathrm{CH}_{4}$ was developed.

- The methane detection utilizes cavity ring-down spectroscopy (CRDS).

- Use of CRDS requires less time, materials and labor than typical of GC analysis.

- Relative standard deviations of $\sim 4 \%$ were achieved at low $\mathrm{nM} \mathrm{CH}_{4}$.

- Applications to seawater and river water are presented.
G R A P H I C A L A B S T R A C T

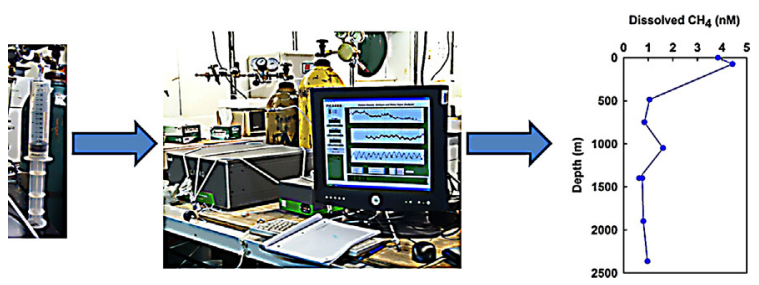

\begin{abstract}
A B S T R A C T
Methane $\left(\mathrm{CH}_{4}\right)$ is the third most abundant greenhouse gas (GHG) but is vastly understudied in comparison to carbon dioxide. Sources and sinks to the atmosphere vary considerably in estimation, including sources such as fresh and marine water systems. A new method to determine dissolved methane concentrations in discrete water samples has been evaluated. By analyzing an equilibrated headspace using laser cavity ring-down spectroscopy (CRDS), low nanomolar dissolved methane concentrations can be determined with high reproducibility (i.e., $0.13 \mathrm{nM}$ detection limit and typical $4 \%$ RSD). While CRDS instruments cost roughly twice that of gas chromatographs (GC) usually used for methane determination, the process presented herein is substantially simpler, faster, and requires fewer materials than GC methods. Typically, $70-\mathrm{mL}$ water samples are equilibrated with an equivalent amount of zero air in plastic syringes. The equilibrated headspace is transferred to a clean, dry syringe and then drawn into a Picarro G2301 CRDS analyzer via the instrument's pump. We demonstrate that this instrument holds a linear calibration into the sub-ppmv methane concentration range and holds a stable calibration for at least two years. Application of the method to shipboard dissolved methane determination in the northern Gulf of Mexico as well as river water is shown. Concentrations spanning nearly six orders of magnitude have been determined with this method.
\end{abstract}

() 2014 Elsevier B.V. All rights reserved.

\section{Introduction}

Methane $\left(\mathrm{CH}_{4}\right)$ is a greenhouse gas (GHG) that is produced by both natural and anthropogenic sources and plays a vital role in

\footnotetext{
* Corresponding author. Tel.: +1 228688 1178; fax: +1 2286881121 .

E-mail address: alan.shiller@usm.edu (A.M. Shiller).
}

atmospheric chemistry [1,2]. Methane is oxidized within the troposphere by hydroxyl radicals, which can produce carbon monoxide, nitrogen dioxide and hydroperoxide [1,3,4]. Within natural waters, methane is affected by chemical, biological and physical processes and has been used as a tracer of submarine groundwater discharge [5].

Sources within the water column are both natural and anthropogenic, but are dominantly a result of the decomposition 
of organic matter [6,7]. Concentrations of dissolved methane in natural waters have previously been found to vary with organic matter content, oxygen availability, salinity, temperature and wind velocity [6,8-10]. High concentrations of methane are typically associated with low oxygen, high organic matter, high stratification and low mixing in the water column [6,8-10]. Freshwater, estuarine and oceanic methane input to the atmosphere is a complex process, with limited observations that date back approximately 50 years [11]. Concentrations of methane are typically within the low nanomolar range in marine waters [11] and sometimes micromolar within groundwaters [5].

Analysis of dissolved methane requires two stages: extraction and analysis. Extraction techniques include adsorbing the gas onto a sorbent, freeze and trap methods, and headspace equilibration. Analysis was initially completed through manometric and microgasometric techniques but these have largely been supplanted by gas chromatography (GC) following headspace equilibration [11]. Recently, however, new methods of methane analysis utilizing near infrared laser absorption spectroscopy have become commercially available. In particular, this paper examines the use of headspace equilibration and cavity ring-down spectroscopy (CRDS) for dissolved methane determination. The CRDS uses a single-frequency laser diode and a cigar-shaped, or elongated, laser cavity defined by three mirrors, providing an effective path length of many kilometers and enabling the ability to measure trace gases in air samples [12]. The CRDS measures light absorption by determining light intensity decay within the cavity over time (ring-down time) [12]. While roughly twice the cost of a GC, the CRDS instrument provides certain advantages over GC, including simplicity of use and removing the need for carrier and detector gases as well as columns.

Previous work with CRDS technology has proven fruitful in many regards to atmospheric and dissolved gases [13-16]. Becker et al. [13] and Yvon-Lewis et al. [14] used flow-through headspace analysis for continuous measurement of dissolved gases in surface ocean waters. Warner et al. [17] described a discrete sample headspace equilibration method using CRDS detection of methane. While useful for groundwater samples with high $\mu \mathrm{M}$ concentrations of dissolved methane, their method suffers from several deficiencies pertinent to wider application. These difficulties include the use of large samples $(900 \mathrm{~mL})$, which can be problematic both in oceanic applications where subsurface sample volumes can be limited by multiinvestigator water demand as well as in field applications where transport of large numbers of liter-sized glass bottles back to the lab can be difficult. Furthermore, we found the manipulation and equilibration of large samples to be difficult, leading to poor accuracy and precision at low nM dissolved methane concentrations typical of oceanic and estuarine waters. This low concentration reproducibility problem is also evident in Warner et al. [17] calibration data. Below, we describe a simple, lower sample volume (typically $70 \mathrm{~mL}$ ) CRDS/headspace equilibration method that yields high precision even at low nM dissolved methane concentrations. The method required calibration and demonstration of the linearity of response of the CRDS at low (sub-ppmv) methane partial pressures not generally utilized in this type of work. Furthermore, by using a CRDS modified with two different absorption response ranges, we extend the dynamic range of the analysis.

\section{Experimental}

The CRDS instrument used in this work was a Picarro, Inc. (Santa Clara, CA) $\mathrm{G} 2301 \mathrm{CO}_{2}, \mathrm{CH}_{4}, \mathrm{H}_{2} \mathrm{O}$ analyzer. The instrument can measure $\mathrm{CH}_{4}$ in air in the $0-20$ ppmv range, though instrumental specifications (e.g., drift $<3$ ppbv over 1 month) are only guaranteed in the 1-3 ppmv range. Our instrument was modified by the manufacturer with an additional extended range mode for determining $\mathrm{CH}_{4}$ up to 1000 ppmv.

For headspace equilibration of natural water samples, $140-\mathrm{mL}$ Monoject $^{\mathrm{TM}}$ plastic syringes (Kendall Healthcare) fitted with 3-way polycarbonate luer lock stopcocks (Cole-Parmer) were filled with $70 \mathrm{~mL}$ sample water and $70 \mathrm{~mL}$ of methane-free zero air (Airgas). Syringes were rinsed with tap water and allowed to air dry before each use. The $70-\mathrm{mL}$ volume of water sample was only altered when methane concentrations exceeded the linear range of the Picarro G2301 CRDS analyzer. Note that at least $\sim 70 \mathrm{~mL}$ of headspace is required in order to obtain a precise result with the G2301. Contamination with atmospheric air was minimized by eliminating bubbles within the syringe. To do so, approximately $50 \mathrm{~mL}$ of sample was initially introduced into the syringe. The syringe was tapped to gather all air bubbles toward the valve. A small amount of ambient air was then introduced while keeping the syringe upright. The air and water were then carefully expelled from the syringe and the rinsing/bubble elimination was repeated twice more before collecting the desired sample volume $(70 \mathrm{~mL}$ for the experiments reported below). Valves were dried fully and a volume of methane-free zero air $(70 \mathrm{~mL}$ for the experiments herein) was added to each sample. Pressure disequilibrium within the sample syringe was alleviated by momentarily opening the 3-way valve after disconnecting it from the cylinder of zero air. A preliminary test suggested that dissolved methane equilibrates with the headspace with a minute or less of vigorous shaking. However, it was desired to have the samples close to room temperature (or at least a known, measured temperature) in order to be able to correctly calculate the methane solubility. Therefore, samples were placed on a shaker table for typically $30 \mathrm{~min}$. This time was extended if the temperature of the sample was not close to that of the lab air; note, however, that precise temperature control is not necessary as methane solubility is not strongly affected by temperature [18]. Temperature uncertainties at equilibration usually result in minimal changes in headspace concentration, with a $10^{\circ} \mathrm{C}$ difference yielding $\sim 5 \%$ error. Salinity is also known to be a factor in methane solubility, though here too the dependency is not strong [18] and uncertainty in salinity of even a few parts-perthousand will cause negligible error in calculating headspace equilibrium. A more thorough discussion of errors associated with headspace equilibration of methane has been presented by Magen et al. [19].

After sample-zero air equilibration, the equilibrated headspace of each sample was transferred to a clean, dry syringe to minimize the possibility of accidental introduction of water into the CRDS. The transfer procedure included a brief "rinsing" of the valve pathway between the two syringes using a little of the headspace gas. Valves and the interior of each transfer syringe were checked to ensure no water was also transferred. The headspace was then drawn into the Picarro G2301 CRDS analyzer by the analyzer's pump. A procedural blank is obtained by transferring $70 \mathrm{~mL}$ of zero air between two syringes before measurement. The blank value was equivalent to a $\sim 0.06 \mathrm{nM}$ concentration of dissolved $\mathrm{CH}_{4}$ or less than $10 \%$ of the concentration of the lowest oceanic $\mathrm{CH}_{4}$ concentrations we have observed. The measurement of $\mathrm{CH}_{4}$ is the "wet" air measurement given by the G2301, since, published solubility relationships are based on water-saturated air and we assume that our equilibration process saturates the headspace with water vapor.

Dissolved concentrations of methane were calculated from headspace concentrations via the solubility equation of Wiesenburg and Guinasso [18] (1) and Henry's Law (2). 


$$
\begin{aligned}
C^{*}= & \exp \left[\ln \left(\left(p C \mathrm{H}_{4} \times 10^{-6}\right)\right)\right. \\
+ & A_{1}+A_{2}\left(\frac{100}{T}\right)+A_{3} \ln \left(\frac{T}{100}\right)+A_{4}\left(\frac{T}{100}\right) \\
& \left.+S^{*}\left\{B_{1}+B_{2}\left(\frac{T}{100}\right)+B_{3}\left(\frac{T}{100}\right)^{2}\right\}\right]
\end{aligned}
$$

$K_{h}=\frac{C^{*} \times 10^{-9}}{p C \mathrm{H}_{4} \times 10^{-6}}$

$$
\begin{aligned}
\mathrm{CH}_{4}(\mathrm{nM})= & {\left[\left(p C \mathrm{H}_{4}-p C \mathrm{H}_{4}^{B}\right) 10^{-6} \times\left(K_{h}+\frac{V_{\text {head }} / V_{\text {water }}}{R T}\right)\right.} \\
& \left.-\left(p C \mathrm{H}_{4}^{\text {Init }} \times 10^{-6}\right) \times \frac{V_{\text {head }} / V_{\text {water }}}{R T}\right] 10^{9}
\end{aligned}
$$

where $\mathrm{pCH}_{4}$ is the concentration (ppmv) of methane in the equilibrated headspace, $p \mathrm{CH}_{4}{ }^{\mathrm{B}}$ is the methane measurement of the procedural blank, $p \mathrm{CH}_{4}{ }^{\text {Init }}$ is the initial methane concentration of the equilibration gas (generally very close to zero for zero air) and $C^{*}$ is the dissolved concentration of methane in equilibrium with $\mathrm{pCH}_{4}$ at temperature $T(\mathrm{~K})$ and salinity $S$. The constants $A_{1}-A_{4}, B_{1}-B_{3}$ are given by Wiesenburg and Guinasso [18]. The volumes of the headspace and water sample are $V_{\text {head }}$ and $V_{\text {water, }}$ respectively, and $R$ is the gas constant. Eq. (3) is thus derived from a mass balance on methane in the equilibrated headspace and water sample, accounting for procedural blanks and any methane initially in the headspace. In principle, with this mass balance equation, one could use ambient air rather than methane-free zero air as the equilibration gas, so long as the ambient air methane concentration is known. However, this is not advisable for low nanomolar dissolved methane concentrations where the methane from the ambient air would far exceed the headspace partial pressure of methane derived from the sample.

\section{Results and discussion}

\subsection{Calibration and method assessment}

As noted above, our version of the G2301 has two measurement modes. The first mode measures methane within a low range (LR) at concentrations up to $20 \mathrm{ppmv}$, though instrument specifications are guaranteed only between 1 and 3 ppmv. This is the standard configuration of the G2301. The second mode measures high methane concentrations (HM) at concentrations up to at least 1000 ppmv. Both modes were tested with a known methane gas concentration of $4.86 \mathrm{ppmv}$ $( \pm 1 \%)$ over a period of $5 \mathrm{~min}$ of continuous flow. HM measured a concentration of $4.97 \mathrm{ppmv}( \pm 2.6 \%)$. LR measured a concentration of $4.93 \mathrm{ppmv}( \pm 0.06 \%)$. The difference between the two modes was $0.8 \%$ and the measured value for the LR mode was $1.4 \%$ higher than the calibrated value of the gas. Calibration of the HM mode was further checked by measuring several high methane lab standards provided by S. Mendes (UCSB) and found to be within $4 \%$ of specification up to at least $2300 \mathrm{ppmv}$ methane.

Drift within the CRDS is minimized by the instrument's actively stabilizing temperature and pressure within the laser cavity. Laser wavelength, sample pressure and temperature are all controlled, which contribute to a typical drift of $<3$ ppbv over 30 days (according to instrument specification). Drift correction is recommended by Picarro every year. However, measurements of a tank of breathing air (1.9 ppmv $\left.\mathrm{CH}_{4}\right)$ and zero air $\left(0 \mathrm{ppmv} \mathrm{CH}_{4}\right)$ showed no noticeable drift over the course of two years, with the relative standard deviation of the average for each year less than the relative standard deviation on a given day $\left( \pm 0.001 \mathrm{ppmv}^{\mathrm{CH}} \mathrm{H}_{4}\right.$.

Headspace equilibration of samples with low nM concentrations of dissolved methane yielded methane concentrations within the headspace less than $0.1 \mathrm{ppmv}$. This is problematic both because the manufacturer guarantees instrument specifications only down to $1 \mathrm{ppmv}$ and because low ( $<0.1 \mathrm{ppmv})$ methane standards are not commercially available. Thus, a test of the linearity and precision of low ppmv/ppbv measurements of $\mathrm{CH}_{4}$ with the CRDS was performed (Fig. 1). Standards were mixed in the lab to test instrument linearity in the low ppmv range using two known gases: breathing air ( $1.9 \mathrm{ppmv})$ diluted with zero air ( $0 \mathrm{ppmv})$. For concentrations greater than $10 \%$ breathing air, a sample syringe (SS) was filled to a specified volume of breathing air after rinsing five times with the breathing air. A transfer syringe (TS) was then filled with zero air also after rinsing five times with zero air and connected to the SS. The TS was opened and a small amount of zero air was used to clear the connected valves and equalize the pressure within the syringe. The SS was opened and the appropriate amount of zero air was added to the SS. When gases were transferred between syringes, the volume within the syringe was adjusted according to the known volume added to the syringe to ensure pressure equilibration. The SS was left alone for an hour to allow the gases to mix.

To make mixtures of $10 \%$ or less breathing air in zero air, a $500 \mathrm{~mL}$ Tedlar $^{\circledR}$ EconoGrab $^{\mathrm{TM}}$ gas bag (Zefon International) was filled with zero air and breathing air to make an approximately $10 \%$ mixture of breathing air in zero air. Prior to equilibrating, the bag was filled with zero air and a vacuum was then used to remove all air. The process of filling and evacuating was repeated three times, ending with a vacuumed gas bag with minimal air or $\mathrm{CH}_{4}$. Syringes were then used to transfer proportional amounts of each gas to the bag. With each consecutive addition, the syringe was rinsed five times with zero air or breathing air and then filled with the corresponding gas to the correct volume. A small volume of gas from the syringe was then used to clear the connection between

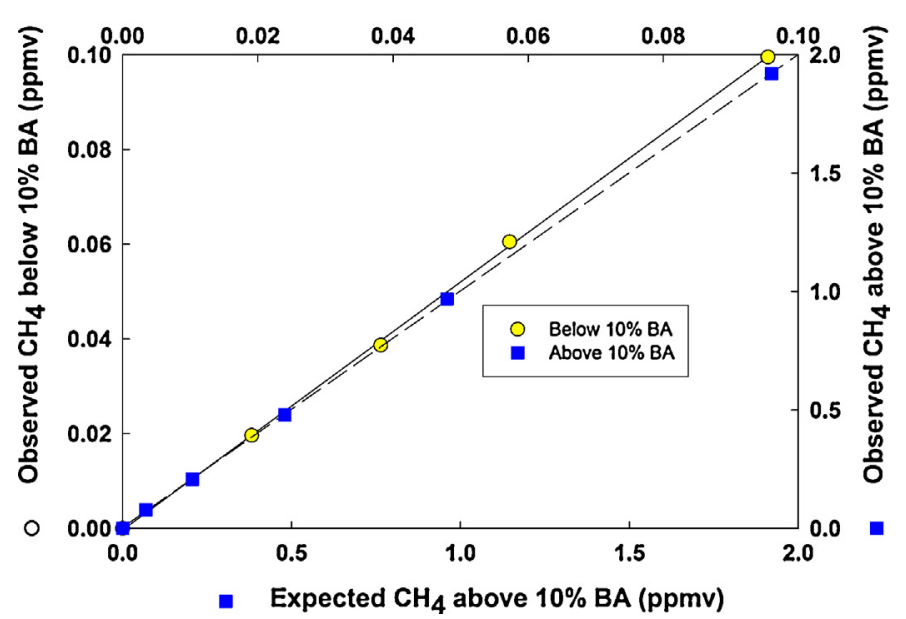

Fig. 1. Linearity test of the Picarro G2301 CRDS analyzer for two ranges/methods of gas dilution (see text). Mixtures of methane free gas (zero air, ZA) and breathing air (1.9 ppmv, BA) were used to generate low methane air concentrations. The slope for mixtures above $10 \%$ breathing air is 0.9989 and the slope for mixtures below $10 \%$ breathing air is 1.046 . 
Table 1

Relative standard deviations (RSD) for tap water samples with $n$ repetitions.

\begin{tabular}{lllll}
\hline Date & $n$ & Equilibration time $(\min )$ & Average $\mathrm{CH}_{4}(\mathrm{nM})$ & $\mathrm{RSD}(\%)$ \\
\hline June 29, 2011 & 20 & $10-60$ & 607 & 2.3 \\
June 30, 2011 & 10 & $10-120$ & 594 & 1.7 \\
July 6, 2011 & 12 & $10-150$ & 484 & 5.7 \\
July 7, 2011 & 12 & $10-120$ & 373 & 5.1 \\
January 31, 2013 & 3 & 15 & 248 & 3.5 \\
January 31, 2013 & 6 & 15 & 175 & 6.3 \\
January 31, 2013 & 5 & 15 & 31 & 5.1 \\
July 18, 2011 & 8 & 60 & 4 & 8.3 \\
\hline
\end{tabular}

the syringe and bag before adding the appropriate amount of gas. The gas bag presented negligible resistance to inflation, so pressure equilibration was not an issue. The bag was left alone for $15 \mathrm{~min}$ to allow the gases to mix. The gas bag was then used as a reservoir of gas to be measured. For each measurement, a small amount of gas from the bag was used to clear the connection between bag and syringe. A volume of $70 \mathrm{~mL}$ of gas from the bag was added to the syringe through the use of the syringe plunger to avoid pressure disequilibration and was then measured using the CRDS.

Results showed a slope of 0.9989 for mixtures greater than $10 \%$ breathing air (i.e., >0.19 ppmv methane) and 1.046 for mixtures less than $10 \%$ (Fig. 1). The coefficients of determination for these data are 0.9999 and 0.9999 , respectively. ANCOVA analysis of the data shows a $p$-value of 1 . This experiment demonstrates the linearity of the G2301's calibration at the low methane concentrations we typically measure in our equilibrated headspace.

The reproducibility of the method was tested using tap water as the sample source and $140-\mathrm{mL}$ syringes with $70 \mathrm{~mL}$ of sample water. Sample water was added to multiple syringes and allowed to equilibrate on a shaker table for varying times. Relative standard deviations averaged about $4 \%$ (see Table 1 ). Samples deviating the most from the average concentration did not correlate with time on the shaker table.

Precision of the method was almost always better than $\pm 10 \%$ for replicate natural water samples, with typical relative standard deviations between replicates of $\pm 4 \%$. By weighing filled syringes, we found that the sample volume error was typically $<1 \mathrm{~mL}$. No difference was observed in the precision of results between fresh and saline samples. The detection limit, based on replicate blanks made by manipulating zero air with no water sample, was $0.13 \mathrm{nM}$. Further tests of the reliability of the method as applied to natural waters are discussed in the following section.

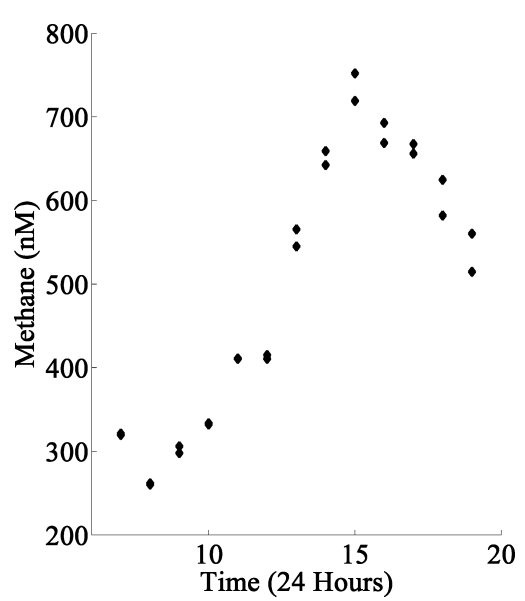

Fig. 2. Analysis of dissolved methane (nM) in replicate samples of East Pearl River (MS) water over a $12 \mathrm{~h}$ period in August 2012

\subsection{Application and performance with natural waters}

An example of the precision of methane analysis with our technique when applied to natural waters having dissolved methane concentrations of hundreds of $\mathrm{nM}$ is shown in Fig. 2. Water samples were collected hourly from the lower East Pearl River at the Stennis Space Center, MS in August 2012. Our sampling location is subject to salt wedge intrusion under summertime low discharge conditions and the dissolved methane in Fig. 2 varied negatively with the river's gauge height, suggesting tidal influence. Samples were taken in replicate and the replicates typically varied by less than $3 \%$. Thus, at these levels, the reproducibility of the method is similar to that of our lab experiments.

Measurements have also been made using this method while at sea. Following the control of the Deepwater Horizon well blowout, a cruise was undertaken in October 2010. Multiple methane profiles were collected in the northern Gulf of Mexico during that cruise and subsequent cruises. All analysis of the samples was completed at sea. An example of the results is shown in Fig. 3 for a station at $28.675^{\circ} \mathrm{N}, 87.650^{\circ} \mathrm{W}$, approx. $70 \mathrm{~km}$ east of the wellhead. A first hydrocast at the station showed an apparent small spike of methane at approx. $1000 \mathrm{~m}$ and a second cast was able to reproduce the narrow spike of methane and additionally demonstrates the precision of the measurements at subnanomolar methane concentrations. The second cast samples between 1050 and $1400 \mathrm{~m}$ depth averaged $0.65 \pm 0.10 \mathrm{nM} \mathrm{CH}_{4}$. These pseudo-replicates (i.e., there is no reason to think that methane was absolutely uniform in this depth range) provide one indication of the method's precision at these low concentrations. Also, of 19 samples having methane $<2.4 \mathrm{nM}$ and collected in replicate during this cruise, the median difference between replicates was $0.17 \mathrm{nM}$ or $12 \%$. Note that the concentrations in this profile are typical of background methane levels previously reported in the northern Gulf of Mexico [20].

We were also able to compare marine dissolved methane determined by our method with replicates determined by colleagues on stored samples using a gas chromatography (GC) method [19]. Fig. 4 shows these results obtained from a July 2014 cruise in the northern Gulf of Mexico near the Deepwater Horizon wellhead as well as near the Mississippi River delta. Note that three samples obviously contaminated with atmospheric methane (not shown) were eliminated from the comparison. A reduced major axis regression provides a slope of 1.013 and an offset of $0.4 \mathrm{nM}$, with the CRDS results being higher. For samples with dissolved methane below $30 \mathrm{nM}$, the offset drops to $0.06 \mathrm{nM}$

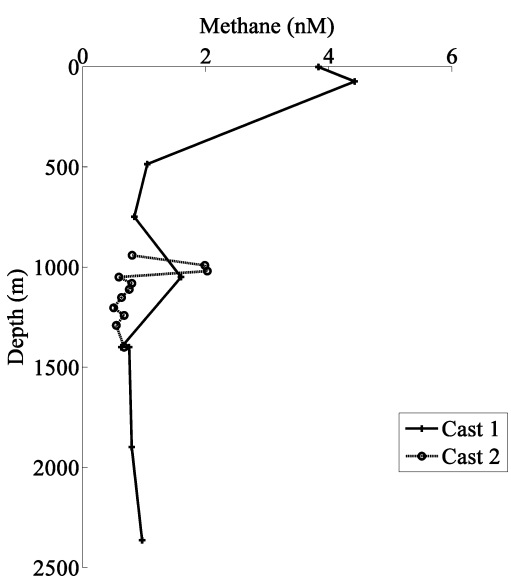

Fig. 3. Dissolved methane (nM) profile in the northern Gulf of Mexico from October 2010. The second cast was performed to provide a more detailed profile of the methane peak at $1000 \mathrm{~m}$. 


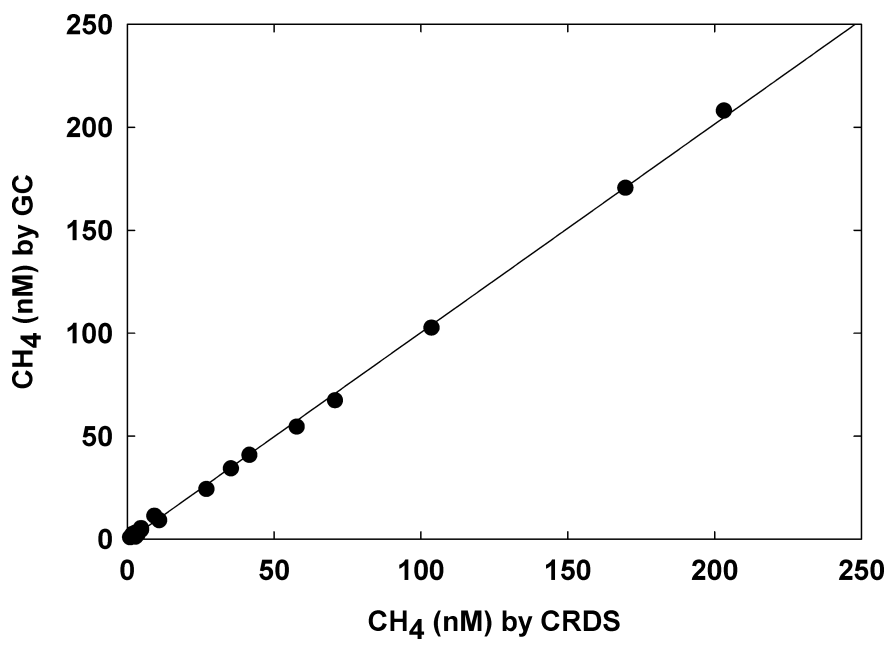

Fig. 4. Comparison of dissolved methane (nM) determined by GC (Magen et al. [19]) and CRDS (this work) in the northern Gulf of Mexico, July 2014. Reduced major axis regression line is shown.

with the CRDS results being lower. The linear correlation coefficient between the two data sets was 0.9992 for the complete 30-replicate sample set. These results indicate that the CRDS method indeed produces methane results comparable to more common GC analysis.

An additional cruise to the Orca Basin in the northern Gulf of Mexico during June 2013 highlights the range and flexibility of the method (Fig. 5). Previous research indicated concentrations of approximately $750 \mu \mathrm{M}$ dissolved $\mathrm{CH}_{4}$ in the deep hyper-saline waters (with salinity approximately $250 \mathrm{~g} \mathrm{~L}^{-1}$ ) of this basin [21]. Minimal mixing with the overlying water results in these high concentrations, which are far outside the range of the Picarro G2301 without great dilution of the sample. Due to the high methane supersaturation of the deep basin samples, additional precautions were taken to prevent gas loss. Upon retrieval into plastic syringes, $60 \mathrm{~mL}$ samples of hypersaline water were immediately and tightly enclosed in plastic wrap to minimize leakage of methane out of sample syringe. Zero air was quickly added to each syringe, which was immediately re-wrapped and placed on a shaker table for approximately $30 \mathrm{~min}$. Upon equilibration, sample headspaces were diluted to approximately 7\% with zero air. Relative standard deviations of these

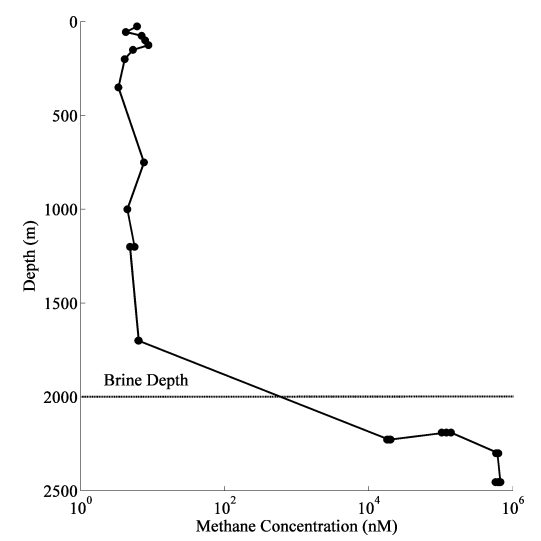

Fig. 5. Dissolved methane (nM) profile in and above the Orca Basin brine, northern Gulf of Mexico, June 2013. Brine depth is at $2000 \mathrm{~m}$. The water column above the brine was consistent with typical methane profiles within the northern Gulf of Mexico [20]. measurements were between 3.4 and 10.6\%. Dissolved methane concentrations within the water column above the brine were 3.3-8.7 nM. Concentrations within the brine increased from $2 \mu \mathrm{M}$ at $1800 \mathrm{~m}$ to $630 \mu \mathrm{M}$ at $2454 \mathrm{~m}$. Measurements just above the brine at $1700 \mathrm{~m}$ were $6 \mathrm{nM}$. These measurements are similar to previously reported concentrations in this basin published by Wiesenburg et al. [21]. The sharp gradient suggests minimal mixing with the overlying water column, as would be expected from the extreme salinity gradient. Overall, dissolved methane concentrations in this profile spanned more than five orders of magnitude.

\section{Conclusions}

The CRDS headspace analysis allows for the measurement of methane both at sea and within the lab. The portability of the instrument, minimal drift and high precision allow for a flexible and simple method of analysis. This particular method also allows for samples to be collected and returned to the lab for analysis, requiring only water collection tools in the field. The requirements of this process are the elimination of air within samples and ensuring no methane generation or consumption prior to analysis. The latter can be achieved through poisoning samples or ensuring the rate of biological activity is low such as by chilling the samples.

Our work also demonstrates the practicality of using the Picarro G2301 for determining very low ppmv $\mathrm{CH}_{4}$ partial pressures. Water samples with varying salinity, in-situ temperature and nM methane concentration have been measured with high precision, typically better than 5\% RSD. These include river, coastal, open ocean and brine samples spanning nearly six orders of magnitude in concentration. The CRDS has been taken to sea on multiple cruises, where data collection and calculations were completed on board. Rapidity and reproducibility are high, which shows great promise in furthering marine methane research, flux estimations and data on global sources.

Measurement of methane in all water types can be made easily and efficiently as long as environmental parameters (salinity and temperature) are known. Although the initial cost of a CRDS instrument is about twice that of a GC, the CRDS requires neither carrier or detector gases nor columns. The method requires little lab equipment and minimal space, which is ideal for analysis at sea. Sample requirements have also been minimized. Because the G2301 measures $p \mathrm{CO}_{2}$ at the same time as methane, there is the potential to extend this method to determination of dissolved $\mathrm{CO}_{2}$, though this would require far more stringent temperature control and measurement.

\section{Acknowledgements}

We thank the captains and crews of the R/V Pelican and R/V Cape Hatteras as well as chief scientists Charlotte Brunner, Kevin Yeager, and Brad Rosenheim. Melissa Gilbert, DongJoo Joung, Kevin Martin and Samantha Wheeler all assisted in the collection of data despite weather conditions and sleep deprivation. We also thank Stephanie Mendes (UCSB) for useful discussion and standards. We thank Jeff Chanton and Cedric Magen (FSU) for sharing the GC methane data. The manuscript was improved by the comments of two reviewers. This work was funded by NSF (OCE-1042934 and OCE-1057726) and the Northern Gulf Institute/BP (10-BP-GRI-USM-01, Task 2).

\section{References}

[1] S. Kirschke, P. Bousquet, P. Ciais, M. Saunois, J. Canadell, E. Dlugokencky, P. Bergamaschi, D. Bergmann, D. Blake, L. Bruhwiler, P. Cameron-Smith, S. Castaldi, F. Chevallier, L. Feng, A. Fraser, M. Heimann, E. Hodson, S. Houweling, 
B. Josse, P. Fraser, P. Krummel, J.F. Lamarque, R. Langenfelds, C. Le Quéré, V. Naik, S. O’Doherty, P. Palmer, I. Pison, D. Plummer, B. Poulter, R. Prinn, M. Rigby, B. Ringeval, M. Santini, M. Schmidt, D. Shindell, I. Simpson, R. Spahni, L. Steele, S. Strode, K. Sudo, S. Szopa, G. van der Werf, A. Voulgarakis, M. van Weele, R. Weiss, J. Williams, G. Zeng, Three decades of global methane sources and sinks, Nat. Geosci. 6 (2013) 813-823.

[2] S. Solomon, D. Qin, M. Manning, Z. Chen, M. Marquis, K.B. Averyt, M. Tignor, H L. Miller, Climate Change 2007: The Physical Science Basis Contribution of Working Group I to the Fourth Assessment Report of the IPCC, vol. 4, Cambridge University Press, 2007.

[3] R. Cicerone, R. Oremland, Biogeochemical aspects of atmospheric methane, Global Biogeochem. Cycles 2 (1988) 299-327.

[4] D. Etheridge, G. Pearman, P. Fraser, Changes in tropospheric methane between 1841 and 1978 from a high accumulation-rate Antarctic ice core, Tellus Ser. B 44B (1992) 282-294.

[5] R. Corbett, J. Chanton, W. Burnett, K. Dillon, C. Rutkowski, Patterns of groundwater discharge into Florida Bay, Limnol. Oceanogr. 44 (1999) 1045-1055.

[6] R. Kiene, Production and consumption of methane in aquatic systems, in: J. Rogers, W. Whitman (Eds.), Microbial Production and Consumption of Greenhouse Gases: Methane, Nitrogen Oxides and Halomethanes, American Society for Microbiology, Washington D.C, 1991, pp. 111-146.

[7] R. Thauer, Biochemistry of methanogenesis: a tribute to Marjory Stephenson: 1998 Marjory Stephenson Prize Lecture, Microbiology 144 (1998) 2377-2406.

[8] G. Abril, N. Iversen, Methane dynamics in a shallow non-tidal estuary (Randers Fjord, Denmark), Mar. Ecol. Prog. Ser. 230 (2002) 171-181.

[9] H. Bange, S. Rapsomanikis, M. Andreae, The Aegean Sea as a source of atmospheric nitrous oxide and methane, Mar. Chem. 53 (1996) 41-49.

[10] D. Sebacher, R. Harriss, K. Bartlett, Methane flux across the air-water interface: air velocity effects, Tellus B 35B (1983) 103-109.
[11] W. Reeburgh, Oceanic methane biogeochemistry, Chem. Rev. 107 (2007) 486-513.

[12] E. Crosson, A cavity ring-down analyzer for measuring atmospheric levels of methane carbon dioxide, and water vapor, Appl. Phys. B: Lasers Opt. 92 (2008) 403-408.

[13] M. Becker, N. Andersen, B. Fiedler, P. Fietzek, A. Körtzinger, T. Steinhoff, G. Friedrichs, Using cavity ring-down spectroscopy for continuous monitoring of $\left({ }^{13} \mathrm{C}\left(\mathrm{CO}_{2}\right)\right.$ and $f \mathrm{CO}_{2}$ in the surface ocean, Limnol. Oceanogr.: Methods $10(2012)$ $752-766$.

[14] S. Yvon-Lewis, L. Hu, J. Kessler, Methane flux to the atmosphere from the Deepwater Horizon oil disaster, Geophys. Res. Lett. 38 (2011) L01602.

[15] A. Alexander, Flowing liquid-sheet jet for cavity ring-down absorption measurements, Anal. Chem. 78 (2006) 5597-5600.

[16] A. Hallock, E. Berman, E. Zare, Direct monitoring of absorption in solution by cavity ring-down spectroscopy, Anal. Chem. 74 (2002) 1741-1743.

[17] N. Warner, T. Kresse, P. Hays, A. Down, J. Karr, R. Jackson, A. Vengosh, Geochemical and isotopic variations in shallow groundwater in areas of the Fayetteville Shale development, north-central Arkansas, App. Geochem. 35 (2013) 207-220.

[18] D. Wiesenburg, N. Guinasso Jr., Equilibrium solubilities of methane, carbon monoxide and hydrogen in water and sea water, J. Chem. Eng. Data 24 (1979) 356-360.

[19] C. Magen, L.L. Lapham, J.W. Polman, K. Marshall, S. Bosman, M. Casso, J.P. Chanton, A simple headspace equilibration method for measuring dissolved methane, Limnol. Oceanogr.: Methods 12 (2014) 637-650.

[20] J.M. Brooks, D.F. Reid, B.B. Bernard, Methane in the upper water column of the Northwestern Gulf of Mexico, J. Geophys. Res. 86 (C11) (1981) 11029-11040.

[21] D. Wiesenburg, J. Brooks, B. Bernard, Biogenic hydrocarbon gases and sulfate reduction in the Orca Basin brine, Geochim. Cosmochim. Acta 49 (1985) 2069-2080. 